\title{
A Randomized Controlled Trial on Assessment of Analgesia on Using Magnesium Sulphate by Different Routes in Patients Undergoing Arthroscopy of Knee under Spinal Anaesthesia
}

\author{
Ch Anil Kumar1, S. Kalyan² \\ 1, 2 Department of Anaesthesiology, Viswabharathi Medical College and Hospital, Kurnool, Andhra Pradesh, India.
}

\section{ABSTRACT}

\section{BACKGROUND}

Adequate pain management has a great importance for smooth postoperative recovery, early hospital discharge and early rehabilitation. In this study, we compare the analgesic effect and possible side effects of different routes of magnesium sulphate administration in cases of spinal anaesthesia for knee arthroscopy.

\section{METHODS}

This is an experimental prospective randomized control study. 196 patients undergoing knee arthroscopy were divided into 4 groups (49 each): Group A: Given bupivacaine intrathecally during spinal anaesthesia. Group B: Given magnesium sulphate $50 \mathrm{mg}$ with bupivacaine intrathecally. Group C: Given magnesium sulphate IV 10 min after intrathecal injection (30 mg/kg MgSo4). Group D: Given magnesium sulphate intra-articular route, $10 \mathrm{~min}$ before the end of surgery ( $800 \mathrm{mgSo} 4$ diluted in $12 \mathrm{ml}$ normal saline $(0.9 \% \mathrm{NaCl})$. Operative time in minutes, VAS at rest and after procedure, time lapse before first analgesic dose after surgery, total dose of rescue analgesics used, pulse rate, mean arterial pressure and side effects were observed and analysed.

\section{RESULTS}

In regards to the lapse of time between end of surgery and first rescue analgesic given, total doses of tramadol used during the 24 hours after the procedure were significantly better in patients given intra-articular magnesium sulphate than other groups $(\mathrm{P}=0.001)$. Patients of Group $\mathrm{C}$ who received IV magnesium sulphate were significantly better than patients who were given intrathecal magnesium sulphate in relation to time taken from end of surgery until first analgesic dose. VAS at rest and during the period of first 24 hours followed by surgery was statistically significant in patients who received intra-articular magnesium sulphate ( $p-0.001)$.

\section{CONCLUSIONS}

Intra-articular administration of magnesium sulphate was observed to be superior to other routes of administration or not using at all. Next to intra-articular route, intravenous magnesium sulphate was found to be superior to intrathecal route in providing post operative analgesia in arthroscopy patients.

\section{KEY WORDS}

Analgesia, Knee Arthroscopy, Pain, Magnesium Sulphate, Intrathecal, Intra-articular

\author{
Corresponding Author: \\ Dr. S. Kalyan, \\ Associate Professor, \\ Department of Anaesthesiology, \\ Viswabharathi Medical College \& Hospital, \\ Kurnool, Andhra Pradesh, India. \\ E-mail: thalithakumidhanya@gmail.com
}

DOI: $10.14260 /$ jemds/2022/18

How to Cite This Article:

Kumar CA, Kalyan S. A randomized controlled trial on assessment of analgesia on using magnesium sulphate by different routes in patients undergoing arthroscopy of knee under spinal anaesthesia. J Evolution Med Dent Sci 2022;11(01):93-97, DOI: $10.14260 /$ jemds/2022/18

Submission 18-12-2021, Peer Review 25-12-2021,

Acceptance 17-01-2022,

Published 25-01-2022.

Copyright (C) 2022 Ch Anil Kumar et al. This is an open access article distributed under Creative Commons Attribution License [Attribution 4.0 International (CC BY 4.0)] 


\section{BACKGROUND}

Magnesium sulphate is used as an analgesic intraoperatively or during immediate postoperative period, as it plays a vital role in pain management. ${ }^{1}$ Its action is on receptors in central nervous system as an antagonist of $\mathrm{N}$-methyl-D-aspartate (NMDA). ${ }^{2}$ Though magnesium sulphate is used as an analgesic for decades, the first randomized control study was conducted only in 1996 when it was used as an adjuvant to other postoperative pain management drugs. ${ }^{3}$ The earlier studies in 2007 gave conflicting opinions. ${ }^{4,5}$ But the recent meta-analyses and systematic review studies proved its positive pain alleviating role in several surgeries.6,7 Usage of magnesium sulphate reduces the dosage and frequency of schedules of opioid drugs according to Albrecht et al. who reviewed 25 randomized controlled studies which include 1461 patients. They concluded that perioperative intravenous magnesium reduced opioid analgesics in the first 24 hours postoperative period without any reported serious adverse effects. The analgesic effects of magnesium in orthopaedic surgery were also extensively studied by Koenig et al. ${ }^{8}$ in 1997 and concluded that magnesium sulphate given intravenously for knee arthroscopic surgery was very useful. The adverse effects of IV use of MgSO4 were also studied by many authors who concluded that they were minimal.9,10,11 Preventive analgesia always reduces pain impulse transmission in the central nervous system and reduces pain felt by the patient. ${ }^{12}$ Magnesium acts as a physiological and pharmacological blocker of NMDA receptors in central nervous system \& can be used in both acute and chronic pain. ${ }^{13}$ The routes of administration of magnesium sulphate were chosen by different authors as intravenous, intrathecal, and epidural given as an adjuvant in regimens of analgesic drugs. ${ }^{14}$ Intra-articular magnesium sulphate was also used in many studies and demonstrated to produce effective postoperative analgesia. ${ }^{15,16}$ Review of literature showed many studies on the role of magnesium sulphate as an analgesic but the studies on the role of different routes of administration of magnesium sulphate are but a few in number.

\section{Objectives}

To compare the three different routes of administration of magnesium sulphate for its analgesic effect in patients undergoing knee arthroscopy under spinal anaesthesia and to observe for possible side effects. To measure the operative time in minutes, VAS at rest and after procedure, time lapse before first analgesic dose after surgery, total dose of rescue analgesics used, pulse rate, mean arterial pressure and side effects.

\section{METHODS}

An experimental prospective randomized control study from January 2017 to December 2019 was conducted at Viswabharathi Medical College, RT Nagar, Penchikalapadu, Kurnool, Andhra Pradesh.
After obtaining ethical committee approval the present study was conducted among 196 patients. Informed written consents were taken from all the patients.

\section{Inclusion Criteria}

1. Patients of both genders aged between 19 years and 55 years.

2. Patients with ASA I and II fitness grading.

3. Patients planned for knee arthroscopy.

4. Patients willing to join the study.

5. Patients who have not received any type of analgesic drugs 6 hours prior to the knee arthroscopy procedure.

\section{Exclusion Criteria}

1. Patients refusing to continue or join the study.

2. Patients refusing spinal anaesthesia.

3. Patients with contra indications for spinal anaesthesia.

4. Patients with previous history of allergy to any of the drugs used in the study.

5. Patients with class, IV and V ASA grading.

6. Patients under the age of 19 years.

7. Patients with cardiac, severe hepatic or renal diseases, abnormal serum electrolytes levels.

A simple random sampling using (www. randomization.com) website was used to allot the patients to the different groups in the study. For all the patients' demographic details were elicited and noted. The age, height and weight were documented. 196 patients were divided equally into four groups (each group having 49 patients. The Group A (49 patients) patients received bupivacaine intrathecally during spinal anaesthesia but no other drug was used. Group B patients (49) received $50 \mathrm{mg}$ Mg sulphate in $0.5 \mathrm{ml}$ (10 \% $\mathrm{Mg}$ sulphate) along with bupivacaine intrathecally. Group C patients (49) after spinal anaesthesia with bupivacaine received intravenous injection of magnesium sulphate $(30 \mathrm{mg} / \mathrm{kg}$ ) in $100 \mathrm{ml}$ saline over $10 \mathrm{~min}$ followed by $10 \mathrm{mg} / \mathrm{kg}$ intravenous infusion over one hour. Group D (49 patients) received in addition to spinal anaesthesia intra-articular injection of $800 \mathrm{mg}$ Mg sulphate (8 $\mathrm{ml}$ of $10 \% \mathrm{Mg}$ sulphate) diluted in $12 \mathrm{ml}$ normal saline $(0.9$ $\% \mathrm{NaCl}) 10 \mathrm{~min}$ before the end of surgery. To monitor and maintain uniform clinical standard; patients whose arthroscopy procedure exceeded 2 hours period, were eliminated from the study. All the patients were trained on Visual Analogue Scale (VAS) graded from 1-10 (10: worst pain; 0 - no pain) of pain prior to surgery.

\section{Procedure}

Patients of all groups were given $0.01 \mathrm{mg} / \mathrm{kg}$ atropine I.M. half an hour before the procedure. Their blood pressure, ECG and oxygenation were continuously monitored using 3 channel monitor. All Patients received 2 mg midazolam, 500 $\mathrm{mL}$ of lactated Ringer's solution i.v. placed in the sitting position. $15 \mathrm{mg}$ bupivacaine $0.5 \%$ was injected intrathecally by 22-gauge spinal needle placed by median or paramedian approach through L3-L4 intervertebral space. Patients were immediately turned to the supine horizontal position. Ten minutes after intrathecal injection, 


\section{The Following Parameters Were Assessed}

1. Operative time in minutes.

2. VAS pain score was measured at rest as well as with passive movement at $4,8,12,16,20$ and 24 postoperatively.

3. An analgesic rescue drug tramadol, dose of injection 50 $\mathrm{mg} / \mathrm{ml}$ intravenously which cannot be repeated within 6 hours was kept ready as a postoperative for analgesia. The rescue analgesic drug was used when the VAS score is more than 5 .

4. Time taken for the required first dose of analgesia postoperatively.

5. Total number of rescue analgesia doses required by the patients.

6. Side effects noticed during the 24 hours post operative period such as nausea, vomiting, pruritus, shivering; fall in respiratory rate (respiratory depression).

7. Development of hypotension or bradycardia was also considered.

\section{Statistical Analysis}

All the data collected was analysed using SPSS version: 14.0. The data was expressed as mean \pm SD, percentage, ANOVA, chi square test $(p<0.05$ ) was considered as statistically significant.

\section{RESULTS}

The demographic data of patients of all the four groups was identical and comparable and there was statistical correlation between them (Table 1).

\begin{tabular}{|cccccc|}
\hline Observation & Group A & Group B & Group C & Group D & P value \\
Mean age-years & 39.5 & 38.20 & 40.15 & 41.50 & 0.328 \\
Mean height-cms & 173.40 & 175.35 & 176.60 & 174.25 & 0.287 \\
Mean weight-kg & 81.35 & 80.55 & 82.90 & 79.85 & 0.410 \\
Table 1. Demographic Data (n-196; Group A-46, Group \\
B-46, Group C-46, Group D-46) \\
\hline
\end{tabular}

\begin{tabular}{|cccccc|}
\hline Observations & Group A & Group B & Group C & Group D & HSD \\
Value \\
Operation time in minutes & 59.45 & 62.45 & 61.50 & 60.40 & 0.5252 \\
& \pm 8.60 & \pm 9.75 & \pm 8.10 & \pm 7.80 & \\
& $285.40 \pm$ & $305.20 \pm$ & $320.70 \pm$ & $448.90 \pm$ & -1.6811 \\
Time lapse for first analgesic & 34.25 & 12.40 & 13.65 & 10.50 & \\
Total doses of rescue & $118.30 \pm$ & 85.20 & 91.32 & 48.65 & 15.033 \\
analgesic drug used in 24 Hrs- & 10.45 & \pm 8.45 & \pm 8.40 & \pm 5.45 & \\
in mg & 04.35 & 04.25 & 03.0 & 02.30 & 2.2673 \\
The mean number of doses of & $\begin{array}{c}\text { mescue analgesic used } \\
\text { resce 1.10 }\end{array} \pm 1.20$ & \pm 2.10 & \pm 0.55 & \\
Table 2. Postoperative Parameters Observed and Their Comparison \\
among the Four Groups (n-196; Group A-49, Group B-49, Group C-49, \\
Group D-49)
\end{tabular}

There was no statistically significant difference between the four groups regarding operative time (Table 2). As regards mean time taken from end of surgery until first analgesic dose: Group D was significantly higher than group B, C and A. However, the time taken was more among patients of Group C than Group B and A (Table 2). The mean total doses of tramadol consumed in the first postoperative 24 hours: Group D patients used tramadol significantly less than the other A, B and C groups. However, the mean total dose was significantly less in Group C patients than Group A and B patients. Among the Groups A and B, B Group patients consumed less tramadol dose than Group A (Table 2). Post hoc Honestly Significance Difference (HSD) using one-way ANOVA method was used to test the significance and the HSD values were found to be significant.

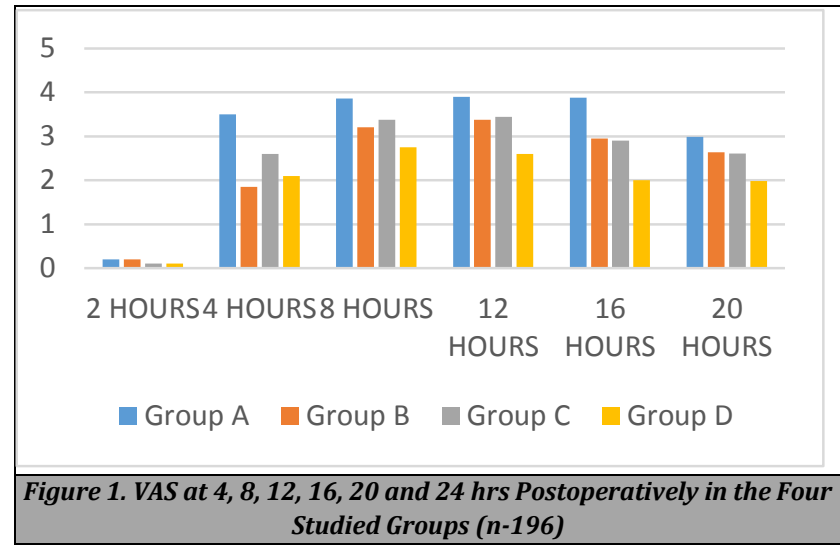

The VAS score measured among the patients of all groups at $4^{\text {th }}$ hourly intervals and the scores showed that the patients of Group D had a significantly lower score than other three groups at all the time intervals (Fig 1). Group C and B patients showed significantly lower VAS scores than Group A at fourth hourly intervals (Fig 1).

\begin{tabular}{|ccccc|}
\hline & Group A & Group B & Group C & Group D \\
\hline 2 hours & 0.2 & 0.2 & 0.1 & 0.1 \\
4 hours & 3.5 & 1.85 & 2.6 & 2.1 \\
8 hours & 3.86 & 3.21 & 3.38 & 2.75 \\
12 hours & 3.9 & 3.38 & 3.44 & 2.6 \\
16 hours & 3.88 & 2.95 & 2.9 & 2 \\
20 hours & 2.99 & 2.64 & 2.61 & 1.98 \\
P value & 0.171 & 0.023 & 0.018 & 0.001 \\
\hline Table 3. VAS at 4, 8, 12, 16, 20 and 24 hrs Postoperatively in the Four \\
\multicolumn{5}{c}{ Studied Groups (n-196) } \\
\hline
\end{tabular}

There were no statistically significant differences in heart rate among the patients of the four groups (Fig. 2, Table 4).

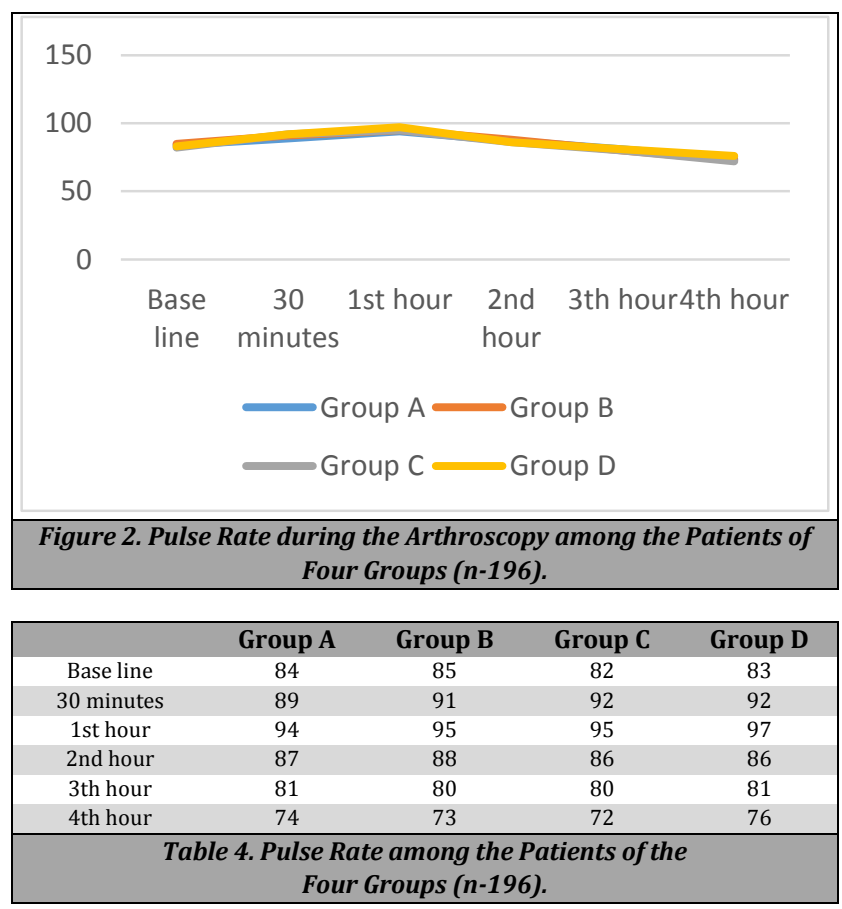

There were no statistically significant differences in mean arterial pressure among patients of the four groups (Fig. 3, Table 5). 


\begin{tabular}{|ccccc|}
\hline & Group A & Group B & Group C & Group D \\
Base line & 87 & 88 & 89 & 90 \\
30 minutes & 93 & 94 & 92 & 94 \\
1st hour & 94 & 95 & 96 & 96 \\
2nd hour & 88 & 86 & 88 & 86 \\
3rd hour & 88 & 88 & 89 & 86 \\
4th hour & 89 & 86 & 89 & 88 \\
\hline Table 5. Mean Arterial Pressure Rate among the Patients of the Four \\
Groups (n-196) \\
\hline \multicolumn{5}{|c}{} \\
\hline
\end{tabular}

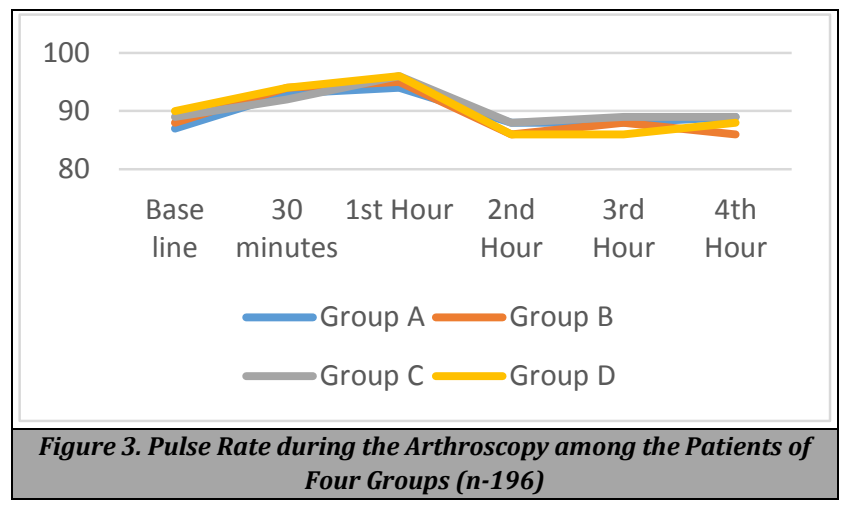

There was no statistical significance in the heart rate, mean arterial pressure and occurrence of side effects among the patients of the four groups (Table 6).

\begin{tabular}{|cccccc|}
\hline Observations & Group A & Group B & Group C & Group D & P value \\
Nausea & $02(04.08 \%)$ & $02(04.08 \%)$ & $03(06.12 \%)$ & $01(02.04 \%)$ & 0.761 \\
Vomiting & $01(02.04 \%)$ & $01(02.04 \%)$ & $02(04.08 \%)$ & $02(04.08 \%)$ & 0.632 \\
Chills and rigors & $01(02.04 \%)$ & $02(04.08 \%)$ & $03(06.12 \%)$ & $02(04.08 \%)$ & 0.315 \\
$\begin{array}{c}\text { Pruritus } \\
\text { Respiratory } \\
\text { depression }\end{array}$ & 00 & 00 & 00 & $01(02.04 \%)$ & 0.221 \\
\hline $\begin{array}{c}\text { Table 6. Side Effects Observed during and after arthroscopy Procedure } \\
\text { (n-196) }\end{array}$ & 0.221 \\
\hline
\end{tabular}

\section{DISCUSSION}

The present study was to review the role of magnesium sulphate in post arthroscopy patients in providing analgesia. Diet is the only source of magnesium in human body and its level falls down after major surgeries. ${ }^{17,18}$ The increased levels of magnesium used in magnesium treatment regimens usually fall down by day 1 to 3.19 The increased postoperative magnesium concentrations due to such regimens could go up to $1.3-1.6 \mathrm{mM}$ without any detectable complications of hypermagnesemia. ${ }^{20}$ Fortunately, the increased levels of magnesium are found to prevent postoperative urinary retention. ${ }^{21}$ Magnesium acts as an analgesic by its antinociceptive effects on NMDA receptors to inhibit them. ${ }^{22}$ The present study was designed to compare the three different routes of administration of magnesium sulphate for its analgesic effect in patients undergoing knee arthroscopy under spinal anaesthesia and to observe for possible side effects. The results of this study showed that intra-articular administration of magnesium sulphate was found to be superior to other routes of administration when spinal anaesthesia was used for knee arthroscopy. In a similar study Elsharnouby and co-workers, ${ }^{23}$ observed that the combination of magnesium sulphate with bupivacaine intrathecally was more effective as an analgesic than using bupivacaine alone in terms of reducing the postoperative pain. The present study also used the similar magnesium sulphate dose as used by Radwan and co-workers, ${ }^{24}$ who concluded that to increase the duration of analgesia, magnesium sulphate was very useful and it also minimizes the dose of opioids drugs for post-operative pain. A study by Liu and co-workers ${ }^{25}$ proved that there were peripheral nociceptive receptors and the effect of NMDA antagonist action of magnesium sulphate inhibits them and input terminals of C-fibres which cause limitation of central processing of pain. Hence it could be concluded that magnesium sulphate has both central and peripheral action on reducing the pain. In another similar study by Banwait and co-workers, ${ }^{26}$ the authors concluded that route of administration magnesium sulphate have its main role on spinal cord NMDA receptors. It could be that such a mechanism available could be the cause for the results observed in this study wherein IV and intrathecal routes of administration of MgS04 were equally comparable to intraarticular route of administration. But the study conducted by $\mathrm{KO}$ and coworkers ${ }^{27}$ found the IV route and intrathecal route to be superior to the intra-articular route of administration of MgSo4 in producing analgesia. The differences in the results of the present study and the study of $\mathrm{KO}$ and co-workers may be due to the different surgical procedures (abdominal hysterectomy, Caesarean operation, and other lower limb surgeries) that were included in their study, whereas the present study was conducted only for arthroscopy procedure. Among the various trials on magnesium sulphate as an analgesic drug, a study showed that the patient's total analgesic satisfaction and their experience during the night after surgery revealed VAS scores were decreased by $56 \%$ and $70 \%$, respectively. ${ }^{28}$ More than $50 \%$ of the studies failed to prove that the systemic $\mathrm{MgSO}_{4}$ usage might be of beneficial effect on pain intensity. Majority of the randomized control studies revealed that intravenous $\mathrm{MgSO}_{4}$ administration on patients who underwent arthroscopic or lower extremity had a positive analgesic effect, but one study showed the patients who underwent spine surgery did not have positive effect. Hence this study concluded that there need to be further investigative studies to correlate potential effects of analgesia between the types of surgeries and mode of administration of $\mathrm{MgSO}_{4}{ }^{29}$ There was always a chance of perception of pain varying in different patients as pain was influenced by a variety of factors like: gender, genetic, psychological and personality behaviours.

\section{CONCLUSIONS}

While using spinal anaesthesia for knee arthroscopy, intraarticular administration of $\mathrm{MgSo} 4$ was superior to IV route and intrathecal routes in regards to VAS score for pain postoperatively. The multiple usage of opioid drugs was minimized.

\section{Limitations}

Fixed dose schedules were used for IV route $(30 \mathrm{mg} / \mathrm{Kg}$ followed by $10 \mathrm{mg} / \mathrm{Kg}$ ), intra-articular route $800 \mathrm{mg}$ magnesium sulphate (8 $\mathrm{ml}$ of $10 \% \mathrm{Mg}$ sulphate) and intrathecal routes $(50 \mathrm{mg}$ ) in the study. Using higher dosage schedules could have given much better confirmatory results. The onset of sensory and motor blockades after spinal 
anaesthesia was not included in intrathecal route administration in this study.

Data sharing statement provided by the authors is available with the full text of this article at jemds.com.

Financial or other competing interests: None.

Disclosure forms provided by the authors are available with the full text of this article at jemds.com.

\section{REFERENCES}

[1] McCarthy RJ, Kroin JS, Tuman KJ, et al. Antinociceptive potentiation and attenuation of tolerance by intrathecal co-infusion of magnesium sulfate and morphine in rats. Anesth Analg 1998;86(4):830-6.

[2] Ascher P, Nowak L. Electrophysiological studies of NMDA receptors. Trends Neurosciences 1987;10(7):284-8.

[3] Tramèr MR, Schneider J, Marti RA, et al. Role of magnesium sulfate in postoperative analgesia. Anesthesiology 1996;84(2):340-7.

[4] Tramèr MR, Glynn CJ. An evaluation of a single dose of magnesium to supplement analgesia after ambulatory surgery: randomized controlled trial. Anesth Analg 2007;104(6):1374-9.

[5] Zarauza R, Saez-Fernandez AN, Iribarren MJ, et al. A comparative study with oral nifedipine, intravenous nimodipine, and magnesium sulfate in postoperative analgesia. Anesth Analg 2000;91(4):938-43.

[6] Albrecht E, Kirkham KR, Liu SS, et al. Peri-operative intravenous administration of magnesium sulphate and postoperative pain: a meta-analysis. Anaesthesia 2013;68(1):79-90.

[7] De Oliveira GS, Castro-Alves LJ, Khan JH, et al. Perioperative systemic magnesium to minimize postoperative pain: a meta-analysis of randomized controlled trials. Anesthesiology 2013;119(1):178-90.

[8] Saritas TB, Borazan H, Okesli S, et al. Is intra-articular magnesium effective for postoperative analgesia in arthroscopic shoulder surgery? Pain Res Manag 2015;20(1):35-8.

[9] Elsharnouby NM, Eid HE, Abou Elezz NF, et al. Intraarticular injection of magnesium sulphate and/or bupivacaine for postoperative analgesia after arthroscopic knee surgery. Anesth Analg 2008;106(5):1548-52.

[10] Radwan YA, Alfeky AA, Faramawi MF. Analgesic effect of intra-articular magnesium sulphate compared with bupivacaine after knee arthroscopic menisectomy. J Adv Res 2013;4(4):355-60.

[11] Liu HT, Hollman MW, Liu WH, et al. Modulation of NMDA receptor function by ketamine and magnesium: Part I. Anesth Analg 2001;92(5):1173-81.

[12] Olapour A, Goushe MR, Soltanzadeh M, et al. Comparison of intravenous magnesium and placepo administration on postoperative pain and analgesic consumption during spinal anesthesia for inguinal hernia repair. J Pharm ScientInnov (JPSI) 2013;2(3):16-9.

[13] James MFM. Magnesium: an emerging drug in anaesthesia. Br J Anaesth 2009;103(4):465-7.

[14] Banwait S, Sharma S, Pawar M, et al. Evaluation of single epidural bolus dose of magnesium as an adjuvant to epidural fentanyl for postoperative analgesia: a prospective, randomized, double-blind study. Saudi J Anaesth 2012;6(3):273-8.

[15] Bondok RS, Abd El-Hady AM. Intra-articular magnesium is effective for postoperative analgesia in arthroscopic knee surgery. Br J Anaesth 2006;97(3):389-92.

[16] Khezri MB, Yaghobi S, Hajikhani M, et al. Comparison of postoperative analgesic effect of intrathecal magnesium and fentanyl added to bupivacaine in patients undergoing lower limb orthopedic surgery. Acta Anaesthesiol Taiwan 2012;50(1):19-24.

[17] Na HS, Shin HJ, Kang SB, et al. Effects of magnesium sulphate on coagulation after laparoscopic colorectal cancer surgery, measured by rotational thromboelastometry (ROTEM(R)). Anaesthesia 2014;69(12):1314-21.

[18] Place HM, Enzenauer RJ, Muff BJ, et al. Hypomagnesemia in postoperative spine fusion patients. Spine (Phila $\mathrm{Pa}$ 1976) 1996;21(19):2268-72.

[19] Do SH. Magnesium: a versatile drug for anesthesiologists. Korean J Anaesthesiol 2013;65(1):4-8.

[20] Hwang JY, Na HS, Jeon YT, et al. I.V. infusion of magnesium sulphate during spinal anaesthesia improves postoperative analgesia. Br J Anaesth 2010;104(1):8993.

[21] Andersson KE, Hedlund P. Pharmacologic perspective on the physiology of the lower urinary tract. Urology 2002;60(5 Suppl 1):13-20.

[22] Moharari RS, Motalebi M, Najafi A, et al. magnesium can decrease postoperative physiological ileus and postoperative pain in major non-laparoscopic gastrointestinal surgeries: a randomized controlled trial. Anesth Pain Med 2013;4(1):e12750.

[23] Elsharnouby NM, Eid HE, AbouElezz NF, et al. Intraarticular injection of magnesium sulphate and/or bupivacaine for postoperative analgesia after arthroscopic knee surgery. Anesth Analg 2008;106(5):1548-52.

[24] Radwan YA, Alfeky AA, Faramawi MF. Analgesic effect of intra-articular magnesium sulphate compared with bupivacaine after knee arthroscopic menisectomy. J Adv Res 2013;4(4):355-60.

[25] Liu HT, Hollman MW, Liu WH, et al. Modulation of NMDA receptor function by ketamine and magnesium: Part I. Anesth Analg 2001;92(5):1173-81.

[26] Banwait S, Sharma S, Pawar M, et al. Evaluation of single epidural bolus dose of magnesium as an adjuvant to epidural fentanyl for postoperative analgesia: a prospective, randomized, double-blind study. Saudi J Anaesth 2012;6(3):273-8.

[27] Ko SH, Lim HR, Kim DC, et al. magnesium sulfate does not reduce postoperative analgesic requirements. Anesthesiology 2001;95(3):640-6.

[28] Al-Hashimi M, Scott S, Griffin-Teall N, et al. Influence of ethnicity on the perception and treatment of early postoperative pain. Br J Pain 2015;9(3):167-72.

[29] Faucett J, Gordon N, Levine J. Differences in postoperative pain severity among four ethnic groups. J Pain Symptom Manag 1994;9(6):383-9. 